\title{
Impact study of the fuel type used on the energy efficiency costs values and harmful emissions generation for small, medium and large container vessels
}

\author{
Viktor Nikiforov ${ }^{1, *}$, and Irina Kostova ${ }^{1}$ \\ ${ }^{1}$ Technical University of Varna, Department of Naval Architecture and Marine Engineering, \\ 9000 Varna, Bulgaria
}

\begin{abstract}
Annually a large amount of goods has been transported over the world and the most of the transportation is carried by seaborne. Although the seaborne trade is considered to be the most efficient - economically and environmentally friendly way of transportation an enormous amount of fossil fuels is used to fulfil the operation of the merchant fleet. Although we are living in times where efforts are directed to improvement of the state of the environment and reduction of the negative impact of the Greenhouse Gases, the fossil fuels still remain the main energy source used to run the internal combustion engines widely used in the ships nowadays. A wellknown fact is that the fuel burning leads to significant harmful emissions generation causing a serious negative effect on the surrounding us environment. The introduced by IMO and MEPC requirements regarding the Greenhouse Gases (GHG) imposes for development and application of new criteria when selecting the ship's propulsion plant. In the current article will be observed three ship groups consisting of real container vessels. The purpose is to analyse the impact caused by the fuel type used in the ship's engines on the GHG generation and the economic indicators related with fuel costs
\end{abstract}

\section{Introduction}

The seaborne trade is a constantly evolving area developing and incorporating new technologies with purpose to turn the shipping into one much cleaner and environmentally friendly industry.

Annually the worldwide shipping uses a large amount of fossil fuels to run the available fleet, which burning in the ship engines is resulting in enormous GHG generation negatively reflecting on the surrounding us environment.

The GHG emissions - including carbon dioxide $\left(\mathrm{CO}_{2}\right)$, methane $\left(\mathrm{CH}_{4}\right)$ and nitrous oxide $\left(\mathrm{N}_{2} \mathrm{O}\right)$, expressed in $\mathrm{CO} 2 \mathrm{e}$ - of total shipping have increased from 977 million tonnes in 2012 to 1,076 million tonnes in 2018 (9.6\% increase). In 2012, 962 million tonnes were $\mathrm{CO}_{2}$ emissions, while in 2018 this amount grew $9.3 \%$ to 1,056 million tonnes of $\mathrm{CO}_{2}$ emissions. The share of shipping emissions in global anthropogenic emissions has increased from $2.76 \%$ in 2012 to $2.89 \%$ in 2018 [1].

The values for global $\mathrm{CO} 2$ emissions and the share that falls for the shipping industry in the period of $2012 \div 2018$ are given in Table 1 (units are in million tonnes).

\footnotetext{
*Corresponding author: v.nikiforov@tu-varna.bg
} 
Table 1. Total Global and Shipping $\mathrm{CO}_{2}$ Emissions (Source - IMO GHG Study 2020)

\begin{tabular}{|c|c|c|c|}
\hline Year & Global CO2 Emissions & $\begin{array}{c}\text { Shipping CO} \mathbf{C O}_{2} \\
\text { Emissions }\end{array}$ & $\begin{array}{c}\text { Shipping as } \\
\text { percentage of global }\end{array}$ \\
\hline 2012 & 34793 & 962 & 2.76 \\
\hline 2013 & 34959 & 957 & 2.74 \\
\hline 2014 & 35225 & 964 & 2.74 \\
\hline 2015 & 35239 & 991 & 2.81 \\
\hline 2016 & 35380 & 1026 & 2.90 \\
\hline 2017 & 35810 & 1064 & 2.97 \\
\hline 2018 & 36573 & 1056 & 2.89 \\
\hline
\end{tabular}

With the development of the modern engine building there is a real opportunity to equip the newbuilding ships or to retrofit the existing fleet (if possible) with new more efficient engines, using fuels which differ from the conventional ones widely used in the shipping nowadays. It is important to note that the modern engines are characterized with lower specific fuel consumption (SFC) when compared to the previous generations. This leads to fuel costs reduction for each separate voyage as well as for each operational period of the ship.

The mentioned fact has two really important aspects for the ship's operation:

- First one could be considered as purely economic - reducing the operational costs related to the fuel, which constitutes a main part from the total expenditures.

- The second one is related to the regulations from harmful emissions generated by shipping, which at the present moment are very strict. Therefore, when taking a decision regarding the main engine type selection it is mandatory to account not only the technical and economic indicators, but the ecological ones as well.

With purpose to reduce the volume of GHG and to improve the state of the environment, the International Maritime Organization (IMO) and Marine Environment Protection Committee (MEPC) established some requirements in connection with the GHG generated by the shipping industry.

In 2011, IMO adopted mandatory technical and operational energy efficiency measures which are expected to significantly reduce the amount of $\mathrm{CO} 2$ emissions from international shipping. These mandatory measures (EEDI/SEEMP) entered into force on 1 January 2013. IMO has adopted important guidelines aimed at supporting implementation of the mandatory measures to increase energy efficiency and reduce GHG emissions from international shipping [2].

In 2018, IMO adopted an initial strategy on the reduction of GHG emissions from ships, setting out a vision which confirms IMO's commitment to reducing GHG emissions from international shipping and to phasing them out as soon as possible [3].

In order to comply with the requirements, set out by the organizations, the ship engine manufacturers developed much more efficient engine types, able to operate with gaseous and conventional fuels, or a combination of them. Increasingly wider applications are finding the so-called Dual-Fuel Engines, which are able to operate with gaseous fuels as LNG and a small portion of diesel oil used as a pilot fuel. 
One of the advantages with gas-fuelled vessels is the ability to adjust operation when the fuel prices rise and modern exhaust-emission limits tighten. Indeed, service experience shows that the dual-fuel engine delivers significant reductions in $\mathrm{CO}_{2}, \mathrm{NO}_{\mathrm{X}}$ and $\mathrm{SO}_{\mathrm{X}}$ emissions [4].

Three ship classes accounted for $55 \%$ of the total shipping $\mathrm{CO}_{2}$ emissions: container ships $(23 \%)$, bulk carriers (19\%), and oil tankers (13\%). These three ship classes also accounted for $84 \%$ of total shipping transport supply (deadweight tonne nautical miles, or dwt-nm) [5].

In Figure 1 are depicted the $\mathrm{CO}_{2}$ emissions generation depending on the ship's class (Source - [5]).

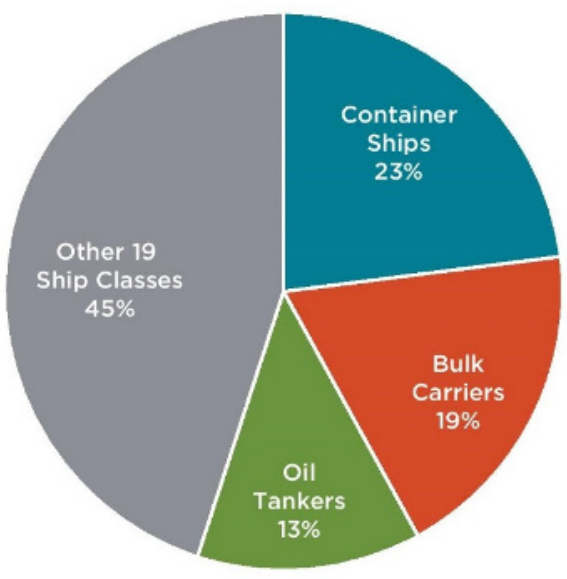

Fig. 1. Shares of $\mathrm{CO}_{2}$ emissions by ship's class

In the current article will be observed three types of container vessels - Feeder, PostPanamax, and ULCV which could be classified respectively as small, medium and large ships.

The aim set out in the current article is to analyse the possibilities for utilizing the dualfuel technology in the composition of the ship power plants and to account the benefits following due to such an intervention. With the calculation performed in the current paper we aim to help for the facilitation in connection with the ship power plant selection.

With purpose to perform that we will use as example existing ships and a substitution of their power plants will be done with regard to account the improvement in GHG emitting only due to the proper engine selection.

\section{Dual-Fuel technology}

Today, ship propulsion is not just about successful movement of the ship in the water. It also includes using the best mode of propulsion to ensure a better safety standard for the marine ecosystem along with cost efficiency [6].

Nowadays a wide range of options intended for the ship propulsion are available. The typical arrangement includes two stroke diesel engines as a prime mover and a number of electric generators propelled by diesel engines ensuring the electrical production

With the stricter requirements introduced by IMO and MEPC regarding the energy efficiency of the ships and the GHG emitting, the shipping industry had been forced to act in direction leading to efficiency improvement of the components used in the ship's propelling systems.

In the past years the marine engine manufacturers introduced modern engines working on the dual-fuel principle able to operate with fuels different from the well-known 
conventional fuels like HFO, MDO and MGO. These engines are able to operate with gaseous fuels like LNG which are considered much cleaner than the conventional ones.

Essentially, the dual-fuel engines don't differ from the well-known diesel engines widely spread in the shipping industry. Like the diesel engines they also provide a wide range of power and speeds ensuring the possibility to propel each ship class available.

There are two main engines concepts for LNG: high and low-pressure. In the highpressure dual-fuel LNG concept, the LNG is injected under high pressure and ignited by a small quantity of diesel. This produces virtually complete combustion of the gas, and thus virtually no un-combusted methane. In the low-pressure system, the LNG is injected under low pressure and ignited by a small amount of diesel. This produces low NOx emissions that meet IMO Tier III, the strictest NOx requirements, while high-pressure LNG requires additional abatement technologies to satisfy IMO Tier III [7].

The main pros when using dual-fuel engines is the opportunity to run the engines with much cleaner fuel like LNG which almost fully eliminate the sulphur oxides $\left(\mathrm{SO}_{\mathrm{X}}\right)$ and Particulate Matter (PM), and also substantially reduce the nitrous oxides $\left(\mathrm{NO}_{\mathrm{X}}\right)$ generated due to the fuel burning in the marine engines.

The common arrangement of the container ships propulsion system consists of a Main Engine (ME) and Diesel Generators (DG), usually one ME and up to 3 DG are involved.

On Figure 2 is shown the typical arrangement commonly used in the container ship propulsion systems.

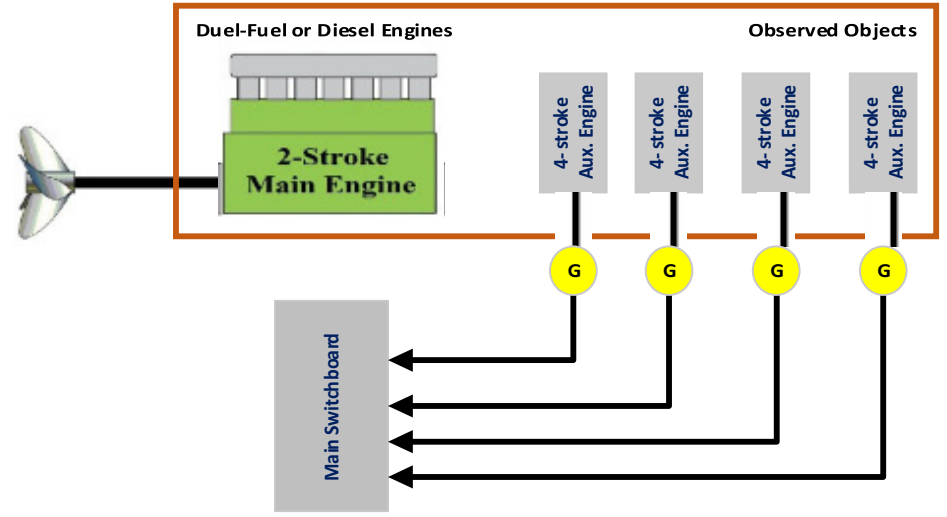

Fig. 2. Typical container ship propulsion system arrangement

\section{Study scenario and calculation methodology}

In the current paper will be observed 3 types of container vessels - small, medium and large respectively. To account the benefits achieved by the dual-fuel propulsion, calculations will be performed first for the initial equipped propulsion systems of each ship, and then for the alternative modern propulsion systems.

For the purpose of current article, we have chosen real container vessels of MSC company, which is one of the biggest companies in the field of container seaborne trade. The initial data necessary for the purpose of the calculations and for the size of the ships are presented in Table 2, more detailed information regarding the chosen ships could be found in [8]. 
Table 2. Initial data for small, medium and large container vessels

\begin{tabular}{|c|c|}
\hline \multicolumn{2}{|r|}{ MSC AMY } \\
\hline ME & MAN B\&W, 6L70MC, $16980 \mathrm{~kW}$ at $108 \mathrm{rpm}$ \\
\hline DG & MAN B\&W, 4 x 6L23/30H, $1050 \mathrm{~kW}$ each \\
\hline TEU & 1683 \\
\hline Deadweight & $22308 \mathrm{t}$ \\
\hline Speed & Max 20.5 knots \\
\hline \multicolumn{2}{|r|}{ MSC ATHENS } \\
\hline ME & MAN B\&W, 9SME-C8.2, $47430 \mathrm{~kW}$ at $78 \mathrm{rpm}$ \\
\hline DG & MAN B\&W, $2 \times 8 \mathrm{~L} 32 / 40-4000 \mathrm{~kW}$ each, $2 \times 9 \mathrm{~L} 32 / 40-4500 \mathrm{~kW}$ each \\
\hline TEU & 8827 \\
\hline Deadweight & $95380 \mathrm{t}$ \\
\hline Speed & Max 22.0 knots \\
\hline \multicolumn{2}{|r|}{ MSC HAMBURG } \\
\hline ME & MAN B\&W, 11S90ME-C9, $59780 \mathrm{~kW}$ at $82 \mathrm{rpm}$ \\
\hline DG & MAN B\&W, 4 x 9L32/40, $4500 \mathrm{~kW}$ each \\
\hline TEU & 16652 \\
\hline Deadweight & $184100 \mathrm{t}$ \\
\hline Speed & Max 23.0 knots \\
\hline
\end{tabular}

With regard to fulfil the goals set, we substitute the main components of the propulsion system (ME and DG) of each considered ship with alternative modern engines with equivalent power working on the Dual-Fuel principle. The rest of the ship's parameters remain unchanged.

In Table 3 are shown the chosen alternative options for each observed ship.

Table 3. Alternative propulsion options for small, medium and large container vessels

\begin{tabular}{|c|c|}
\hline \multicolumn{2}{|r|}{ MSC AMY } \\
\hline $\mathrm{ME}$ & MAN B\&W, 7G60ME-C10.5-GI, $16980 \mathrm{~kW}$ at $98 \mathrm{rpm}$ \\
\hline DG & MAN B\&W, 4 x 8L23/30DF, $1000 \mathrm{~kW}$ each \\
\hline \multicolumn{2}{|r|}{ MSC ATHENS } \\
\hline ME & MAN B\&W, 9G90ME-C10.5-GI, $47430 \mathrm{~kW}$ at $78 \mathrm{rpm}$ \\
\hline DG & MAN B\&W, $2 \times 8 \mathrm{~L} 35 / 44 \mathrm{DF}+2 \mathrm{x} 9 \mathrm{~L} 35 / 44 \mathrm{DF}, 4080 \mathrm{~kW}+4590 \mathrm{~kW}$ each \\
\hline \multicolumn{2}{|r|}{ MSC HAMBURG } \\
\hline ME & MAN B\&W, 11G95ME-C10.5-GI, $59780 \mathrm{~kW}$ at $82 \mathrm{rpm}$ \\
\hline DG & MAN B\&W, 4 x 9L35/44DF, $4590 \mathrm{~kW}$ each \\
\hline
\end{tabular}




\section{Energy Costs Calculation}

Amongst the most important parameters which each marine engine could be described with are its power, speed and specific fuel consumption (SFC).

The fuel consumption represents the basic value used to account the economy of each marine propulsion system.

The main power propulsion plant selection primarily affects the fuel/lubricating oil expenses and maintenance costs i.e., $57 \%$ of the operating cost [9]

To calculate the amount of fuel used for the observed period, the following formulas has been used:

$F C_{(S)}=\left(\tau_{S} \times 24 \times P_{B(M E)} \times S F C_{M E}\right) \times 10^{-6}+\left(\tau_{S} \times 24 \times P_{B(A E)} \times S F C_{A E} \times \sum A E\right) \times$ $10^{-6}$

Where:

$\mathrm{FC}_{(\mathrm{S})}$ - total fuel consumption of the ship in sailing period, [tonnes];

$\tau_{\mathrm{S}}-$ time spent at sea, [days];

$\mathrm{P}_{\mathrm{B}(\mathrm{ME})}$ - main engine power, $[\mathrm{kW}]$;

$\mathrm{SFC}_{\mathrm{ME}}$ - main engine fuel consumption, $[\mathrm{g} / \mathrm{kWh}]$;

$\mathrm{P}_{\mathrm{B}(\mathrm{AE})}$ - auxiliary engine power, $[\mathrm{kW}]$;

$\mathrm{SFC}_{\mathrm{AE}}$ - auxiliary engine fuel consumption, $[\mathrm{g} / \mathrm{kWh}]$.

Where:

$$
F C_{(P)}=\left(\tau_{P} \times 24 \times P_{B(A E)} \times S F C_{A E} \times \sum A E\right) \times 10^{-6}
$$

$\mathrm{FC}_{(\mathrm{P})}$ - total fuel consumption at port stay, [tonnes];

$\tau_{\mathrm{P}}-$ time spent at port, [days].

Where:

$$
F C_{(T)}=F C_{(S)}+F C_{(P)}
$$

$\mathrm{FC}_{(\mathrm{T})}-$ total fuel consumption for the observed period, [tonnes].

With purpose to find the energy costs regarding the fuel type used for the observed in the current paper period, the following equation has been used:

Where:

$$
E C=F C_{(T)} \times P R_{F O}
$$

EC - energy costs [USD];

$\mathrm{PR}_{\mathrm{FO}}$ - fuel price, [USD].

With purpose to the calculations performance, the following assumptions have been considered:

- ME power and SFOC at $75 \%$;

- Diesel ME operates with HFO, Dual-Fuel ME operates with LNG and MDO as Pilot Fuel;

- DG power and SFOC at 50\%.

- Diesel Generators operates with MDO, Dual-Fuel Generators operates with LNG and MDO as Pilot Fuel;

- ME in operation only when sailing;

- Number of DG in operation when sailing - 2 x 50\% Power;

- Number of DG in operation at port stay - 2 x 50\% Power;

- Observed period - 1 year;

- Time spent at sea - $80 \%$ or approximately 292 days; 
- Time spent at port $-20 \%$ or approximately 73 days.

The calculations concerning the energy costs strictly depends on the fuel prices. The fuel prices vary depending on the sailing region and ports visited. For the purpose of our calculations will be considered the global average prices for the last six months $(01.12 .20 \div 31.05 .21)$ for HFO and MDO based on [10], and the average prices for the same period for LNG at Henry Hub based on [11].

The information concerning the specific fuel oil consumption of the ME and DG is based on the relevant engines project guides and with the help of CEAS (Computerized Engine Application System) application provided for free use on the official website of the company MAN B\&W.

In Table 4 are given the input data necessary for the calculations regarding the amount of fuel used and the energy costs for the observed period.

All of the values are according to the assumptions set earlier in the current paper.

Table 4. Input data necessary for the calculations of fuel consumption and energy costs for the observed ships

\begin{tabular}{|c|c|c|c|}
\hline Ship & MSC AMY & MSC ATHENS & $\begin{array}{c}\text { MSC } \\
\text { HAMBURG }\end{array}$ \\
\hline $\mathrm{P}_{\mathrm{B}(\mathrm{ME})},[\mathrm{kW}]$ at $(75 \%)$ & 12735 & 35572.5 & 44835 \\
\hline $\mathrm{SFC}_{\mathrm{ME}}$ (intl.), $[\mathrm{g} / \mathrm{kWh}]$ at $75 \%$ & 170.5 (HFO) & $159.5(\mathrm{HFO})$ & 159.1 (HFO) \\
\hline $\mathrm{SFC}_{\mathrm{ME}}$ (alt.), $[\mathrm{g} / \mathrm{kWh}]$ at $75 \%$ & $\begin{array}{l}128.2(\mathrm{LNG}) \\
3.34(\mathrm{MDO})\end{array}$ & $\begin{array}{l}126.9(\mathrm{LNG}) \\
3.36(\mathrm{MDO})\end{array}$ & $\begin{array}{l}121.5(\mathrm{LNG}) \\
3.70(\mathrm{MDO})\end{array}$ \\
\hline $\mathrm{P}_{\mathrm{B}(\mathrm{AE})},[\mathrm{kW}]$ at $(50 \%)$ & 525 & 2125 & 2250 \\
\hline $\mathrm{SFC}_{\mathrm{AE}}$ (intl.), $[\mathrm{g} / \mathrm{kWh}]$ at $50 \%$ & $\begin{array}{c}196.5 \\
(\mathrm{MDO})\end{array}$ & $\begin{array}{c}197.0 \\
(\mathrm{MDO})\end{array}$ & $\begin{array}{c}197.0 \\
(\mathrm{MDO})\end{array}$ \\
\hline $\mathrm{SFC}_{\mathrm{AE}}$ (alt.), $[\mathrm{g} / \mathrm{kWh}]$ at $50 \%$ & $\begin{array}{c}206.1(\mathrm{LNG}) \\
3.60(\mathrm{MDO})\end{array}$ & $\begin{array}{l}193.5(\mathrm{LNG}) \\
3.80(\mathrm{MDO})\end{array}$ & $\begin{array}{l}193.5 \text { (LNG) } \\
3.80 \text { (MDO) }\end{array}$ \\
\hline HFO Price [\$/tonne] & \multicolumn{3}{|c|}{402.50} \\
\hline MDO Price [\$/tonne] & \multicolumn{3}{|c|}{577.50} \\
\hline LNG Price [\$/tonne] & \multicolumn{3}{|c|}{168.35} \\
\hline
\end{tabular}

\section{Harmful Emissions Quantification}

The FC and the energy costs arising from the former are only the one side of the coin. The other side is the ecology and the influence on the surrounding us environment rendered by the fuel burning in the internal combustion engines. The aim set in front of each shipping company and the shipping society at all is to reduce the harmful emissions generation and therefore the negative impact caused by them.

Quantification of the $\mathrm{CO}_{2}, \mathrm{NO}_{\mathrm{X}}, \mathrm{SO}_{\mathrm{X}}$ and $\mathrm{PM}$ are based on the fuel total fuel consumption calculated and the values for estimation the harmful emissions given in [8] and [9].

With purpose of the calculations performed, the following assumptions have been considered:

- HFO with sulfur content $3.5 \%$;

- $\mathrm{MDO}$ with sulfur content $0.5 \%$ when sailing;

- MDO with sulfur content $0.1 \%$ at port stay;

- LNG Calorific Value - 48000 kJ/kg; 
- ME considered as slow-speed engine;

- $\mathrm{AE}$ considered as medium-speed engine.

With purpose to estimate the GHG emissions emitted by the observed ships for the period set, the following formulas has been used:

Where:

$$
C O_{2}=\left(F C_{(T, M E)}+F C_{(T, A E)}\right) \times E_{F(C O 2)}
$$

$\mathrm{CO}_{2}$ - carbon dioxide emissions, [t];

$\mathrm{FC}_{(\mathrm{T}, \mathrm{ME})}$ - total $\mathrm{FC}$ of main engine, $[\mathrm{t}]$;

$\mathrm{FC}_{(\mathrm{T}, \mathrm{AE})}-$ total $\mathrm{FC}$ of auxiliary engine, $[\mathrm{t}]$;

$\mathrm{E}_{\mathrm{F}(\mathrm{CO} 2)}$ - emission factor for $\mathrm{CO}_{2}[\mathrm{~kg} / \mathrm{t}$ fuel $]$.

Where:

$$
S O_{X}=\left(F C_{(T, M E)}+F C_{(T, A E)}\right) \times E_{F(S O X)}
$$

$\mathrm{SO}_{\mathrm{X}}$ - sulfur oxides emissions, [t];

$\mathrm{E}_{\mathrm{F}(\mathrm{SOX})}$ - emission factor for $\mathrm{SO}_{\mathrm{X}}[\mathrm{kg} / \mathrm{t}$ fuel $]$.

Where:

$$
N O_{X}=\left(F C_{(T, M E)}+F C_{(T, A E)}\right) \times E_{F(N O X)}
$$

$\mathrm{NO}_{\mathrm{X}}$ - nitrogen oxides emissions, [t];

$\mathrm{E}_{\mathrm{F}(\mathrm{NOX})}-$ emission factor for $\mathrm{NO}_{\mathrm{X}}[\mathrm{kg} / \mathrm{t}$ fuel $]$.

$$
P M=\left(F C_{(T, M E)}+F C_{(T, A E)}\right) \times E_{F(P M)}
$$

Where:

$\mathrm{PM}$ - particulate matters emissions, [t];

$\mathrm{E}_{\mathrm{F}(\mathrm{PM})}-$ emission factor for PM $[\mathrm{kg} / \mathrm{t}$ fuel].

In Table 5 are given the emission factor values in necessary for GHG estimation. Values are based on [12] - Table 3 and [13] - Table C.5.

Table 5. Fuel emission factors

\begin{tabular}{|c|c|c|c|}
\hline$/$ & HFO & MDO & LNG \\
\hline $\mathbf{E}_{\mathbf{F}(\mathbf{C O} 2)}$ & 3170 & 3170 & 2688 \\
\hline $\mathbf{E}_{\mathbf{F}(\mathrm{SOX})}$ & $20 \times \mathrm{S} \%$ & $20 \times \mathrm{S} \%$ & 0.027 \\
\hline $\mathbf{E}_{\mathbf{F}(\mathbf{N O X}),}$ Slow Speed & 87 & 87 & 8.16 \\
\hline $\mathbf{E}_{\mathbf{F}(\mathbf{N O X}), \text { Medium Speed }}$ & 57 & 57 & 5.35 \\
\hline $\mathbf{E}_{\mathrm{F}(\mathbf{P M})}$ & 7.6 & 7.6 & 0.21 \\
\hline
\end{tabular}

\section{Study results}

In Table 6 are shown the results attained by equations (1), (2) and (3) regarding the fuel used for the parameters set in Chapter 3.

Table 6 Fuel consumption for operation the vessels for period of 1 year

\begin{tabular}{|l|c|c|}
\hline \multicolumn{3}{|c|}{ MSC AMY } \\
\hline & ME FC [tonnes] & AE FC [tonnes] \\
\hline Initial & $15217 \mathrm{HFO}$ & $1445 \mathrm{MDO}$ \\
\hline Alternative & $11441 \mathrm{LNG}+298 \mathrm{MDO}$ & $3033 \mathrm{LNG}+53 \mathrm{MDO}$ \\
\hline \multicolumn{3}{|c|}{ MSC ATHENS } \\
\hline
\end{tabular}




\begin{tabular}{|l|c|c|}
\hline Initial & $39762 \mathrm{HFO}$ & $11735 \mathrm{MDO}$ \\
\hline Alternative & $31635 \mathrm{LNG}+838 \mathrm{MDO}$ & $11526 \mathrm{LNG}+226 \mathrm{MDO}$ \\
\hline \multicolumn{3}{|c|}{ MSC HAMB URG } \\
\hline & ME FC [tonnes] & AE FC [tonnes] \\
\hline Initial & $49990 \mathrm{HFO}$ & $12425 \mathrm{MDO}$ \\
\hline Alternative & $38176 \mathrm{LNG}+1163 \mathrm{MDO}$ & $12204 \mathrm{LNG}+240 \mathrm{MDO}$ \\
\hline
\end{tabular}

In Table 7 are shown the energy costs regarding the fuel used for operation the ships in a period of 1 year. The results are derived by equation (4)

Table 7. Energy costs for operating the ships in a period of 1 year with both propulsion options

\begin{tabular}{|c|c|c|c|}
\hline \multicolumn{4}{|c|}{$M S C A M Y$} \\
\hline \multirow{2}{*}{ Initial } & HFO Costs [\$] & MDO Costs [\$] & Total Costs [\$] \\
\hline & 6124681 & 1612212 & 7736893 \\
\hline \multirow{2}{*}{ Alternative } & LNG Costs [\$] & MDO Costs [\$] & Total Costs [\$] \\
\hline & 2436797 & 195716 & 2632513 \\
\hline \multicolumn{4}{|c|}{ MSC ATHENS } \\
\hline \multirow{2}{*}{ Initial } & HFO Costs [\$] & MDO Costs [\$] & Total Costs [\$] \\
\hline & 16004241 & 6542207 & 22456448 \\
\hline \multirow{2}{*}{ Alternative } & LNG Costs [\$] & MDO Costs [\$] & Total Costs [\$] \\
\hline & 7266249 & 593169 & 7859410 \\
\hline \multicolumn{4}{|c|}{ MSC HAMBURG } \\
\hline \multirow{2}{*}{ Initial } & HFO Costs [\$] & MDO Costs [\$] & Total Costs [\$] \\
\hline & 20120899 & 6927038 & 27047937 \\
\hline \multirow{2}{*}{ Alternative } & LNG Costs [\$] & MDO Costs [\$] & Total Costs [\$] \\
\hline & 8481505 & 781743 & 9263248 \\
\hline
\end{tabular}

Note: The fuel costs may vary depending on the sailing region of the ships, therefore the energy costs savings could be quite different.

In Figure 3 is depicted the percentage reduction of the energy costs achieved due to the fuel type selection for the ship's propulsion system for period of 1 year.

\section{Energy Costs Reduction}

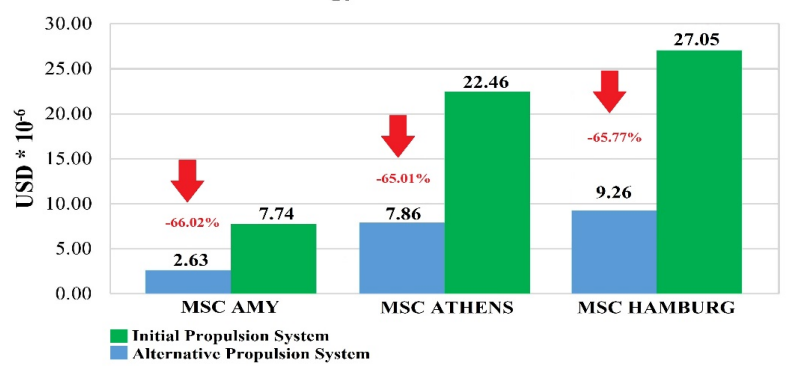

Fig. 3. Energy costs reduction level in percentages 
In Table 8 are given the quantified values for harmuful gases and substances emitted into the atmosphere due to the fuel burning. The calculations are performed by equations (5), (6), (7) and (8).

Table 8. GHG Emissions separated due to the operation of the ships for period of 1 year

\begin{tabular}{|c|c|c|c|c|}
\hline Observed object & $\mathrm{CO}_{2}$ & SOx & NOx & PM \\
\hline $\begin{array}{l}\text { MSC AMY } \\
\text { Initial }\end{array}$ & 57403.8 & 1082.5 & 1488.7 & 137.6 \\
\hline $\begin{array}{l}\text { MSC AMY } \\
\text { Alternative }\end{array}$ & 40020.6 & 3.7 & 129.6 & 5.7 \\
\hline $\begin{array}{c}\text { MSC ATHENS } \\
\text { Initial }\end{array}$ & 163245.5 & 2853.8 & 4128.2 & 391.4 \\
\hline $\begin{array}{l}\text { MSC ATHENS } \\
\text { Alternative }\end{array}$ & 119391.1 & 10.9 & 380.5 & 17.2 \\
\hline$\underset{\substack{\text { Initial } \\
\text { MSC HAMBURG }}}{ }$ & 197855.5 & 3573.8 & 5057.4 & 474.4 \\
\hline $\begin{array}{c}\text { MSC HAMBURG } \\
\text { Alternative }\end{array}$ & 139867.0 & 14.4 & 402.1 & 21.2 \\
\hline
\end{tabular}

Note: All units are in metric tonnes.

In Figures 4, 5, 6 and 7 is depicted the percentage reduction of the GHG emissions achieved due to the fuel type selection for the ship's propulsion system for period of 1 year.

$\mathrm{CO}_{2}$ Emissions Reduction

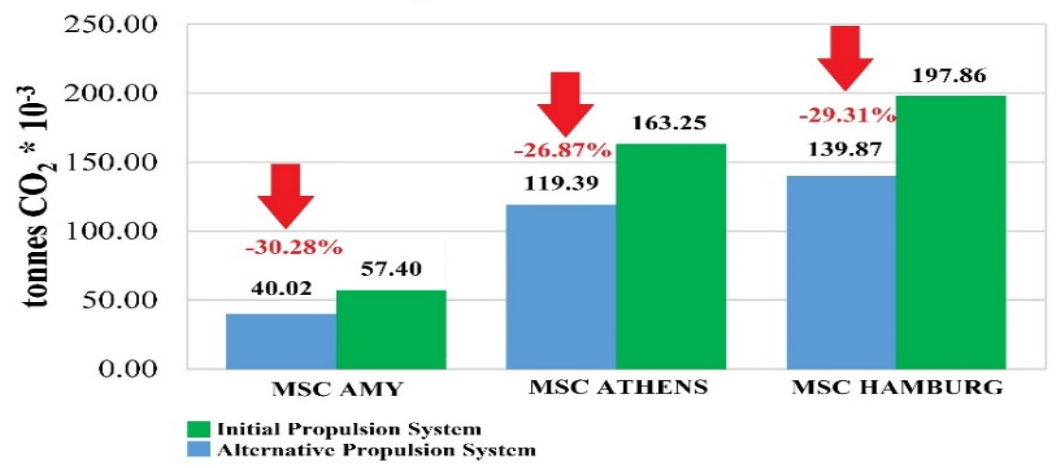

Fig. 4. $\mathrm{CO}_{2}$ Emissions reduction level in percentages 


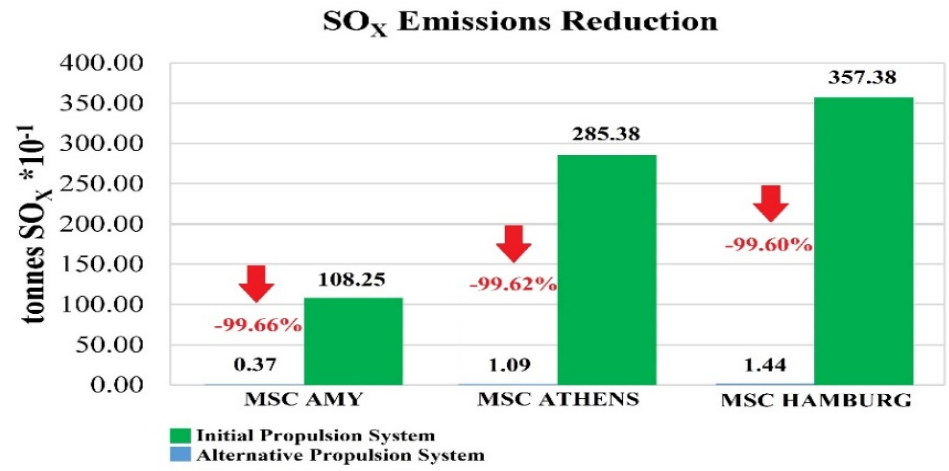

Fig. 5. SOx Emissions reduction level in percentages
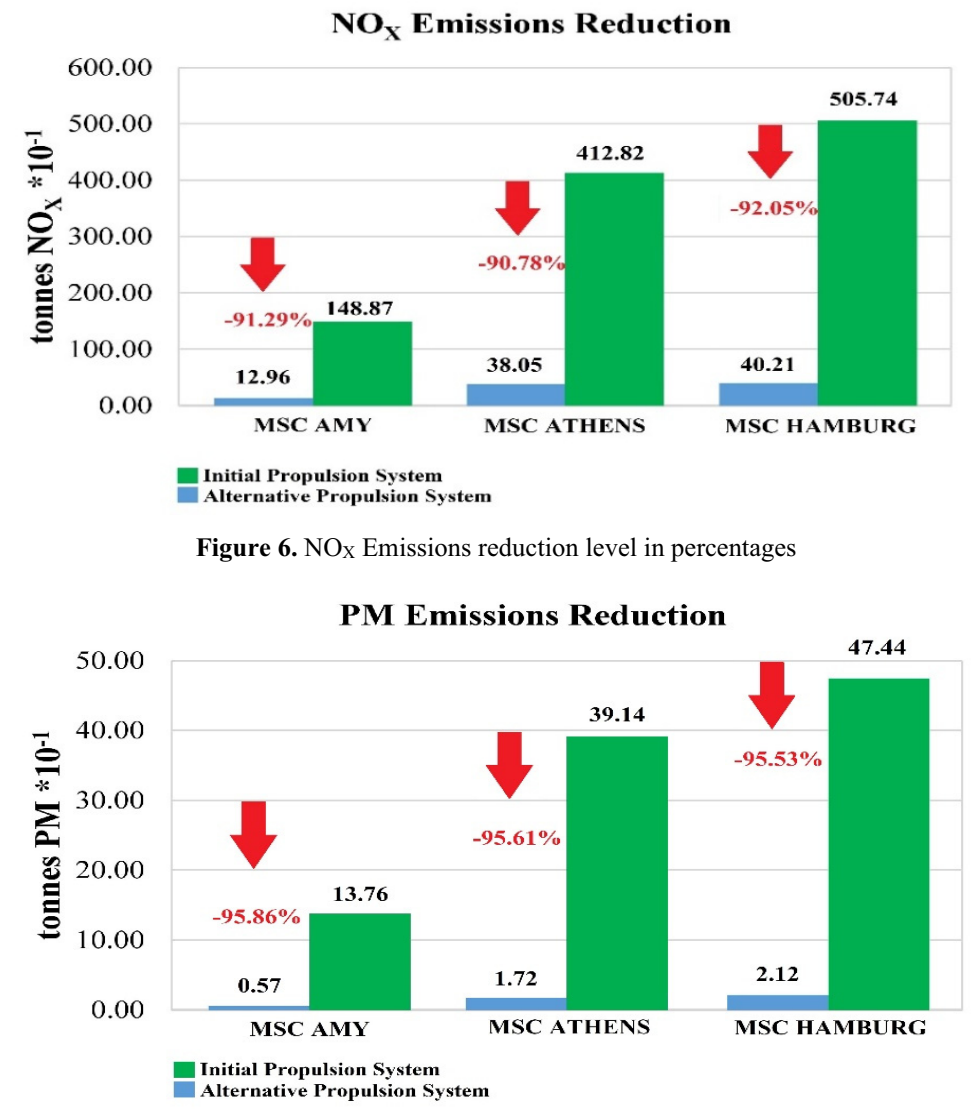

Fig. 7. PM Emissions reduction level in percentages 


\section{Conclusions}

In the current study three types of container vessels has been observed. For each ship the initial equipped and alternative modern propulsion systems has been studied. Calculations regarding the energy costs and GHG emitting has been performed with purpose to make an assesment of the ecology performance of each ship.

Based on the calculation methodology set out in Chapter 3 a significant advantages of the modern dual-fuel engines over the conventional diesel engines widely used in the shipping has been found.

The fuel consumption forming a major part of the energy costs of each ship is significant reduced due to using a dual-fuel technology. An average reducing of the energy costs with $65.6 \%$ is observed based on the results published in Chapter 4.

Along with the notable annual fuel consumption and energy costs reduction, the less environment pollution rendered due to use of less polluting fuels should not be neglected.

Due to the methodology set out in Chapter III also and remarkable GHG reduction has been accounted. An average reduction of main GHG gases like $\mathrm{CO}_{2}, \mathrm{SO}_{\mathrm{X}}, \mathrm{NO}_{\mathrm{X}}$ and $\mathrm{PM}$ respectively with $28.82 \%, 99.63 \%, 91.37 \%$ and $95.67 \%$ is observed. The results from the conducted study displaying a significant reducing of the $\mathrm{CO}_{2}$ and $\mathrm{NO}_{\mathrm{X}}$, and also almost full elimination of the $\mathrm{SO}_{\mathrm{X}}$ and $\mathrm{PM}$ when using dual-fual engines.

Owing to the switching to modern propulsion systems working on Dual-Fuel an option is given to the shipowners to significantly reduce their fuel expenditures as along with that to help for state of the environment improvement. Dual-Fuel technology likewise contributes to fulfil the stricter energy efficiency requirements introduced by IMO.

This work was performed within Project NP8/2021 from the Research Plan of the Technical University of Varna, financed by the State Budget. The first author has been funded in the frame of the Bulgarian National Science Program "Young Scientists and Postdoctoral Students 2021" (Council of Ministers' Decisions No. 577 / 16.08.2018).

\section{References}

1. IMO, Fourth IMO GHG Study 2020, Executive Summary (2020)

2. https://www.imo.org/en/OurWork/Environment/Pages/AirPollution-Default.aspx

3. https://www.imo.org/en/MediaCentre/HotTopics/Pages/Reducing-greenhouse-gasemissions-from-ships.aspx

4. MAN Energy Solutions, MAN B\&W ME-GI Installation in Very Large or Ultra Large Container Vessels (2018)

5. N. Olmer, B. Comer, B. Roy, X. Mao, D. Rutherford, GREENHOUSE GAS EMISSIONS FROM GLOBAL SHIPPING, 2013-2015 (International Council on Clean Transportation 2017)

6. Sharda, www.marineinsight.com, Different Types of Marine Propulsion Systems Used in the Shipping World (2021)

7. E. Lindstad, T. Ingebrigtsen Bo, Potential Power Setups, Fuels and Hull Designs Capable of Satisfying Future EEDI Requirements (2018)

8. https:/www.scheepvaartwest.be/CMS/index.php/containerships

9. G. M. Saha, The Technical and Economical Aspect of Marine Engine Selection (1996, World Maritime University)

10. https://shipandbunker.com/: visited July 2021

11. https://www.eia.gov/dnav/ng/hist/rngwhhdM.html: visited July 2021 
12. K. Spoof-Tuomi, S. Niemi, Environmental and Economic Evaluation of Fuel Choices for Short Sea Shipping (2019)

13. Entec UK Limited, Quantification of Emissions from Ships Associated with the Ship Movements Between Ports in European Community (2002, Final Report) 